\title{
Does oral dryness influence quality of life? Current perspectives in elderly dental care
}

\author{
Katarzyna Skośkiewicz-Malinowska, ${ }^{1, A-D, F}$, Barbara Malicka, ${ }^{1, A, B, D, F}$, \\ Marek Ziętek ${ }^{2, A, D-F}$, Urszula Kaczmarek ${ }^{1, A, D-F}$ \\ ${ }^{1}$ Department of Conservative Dentistry and Pedodontics, Wroclaw Medical University, Poland \\ 2 Department of Periodontology, Wroclaw Medical University, Poland \\ A - research concept and design; $\mathrm{B}$ - collection and/or assembly of data; $\mathrm{C}$ - data analysis and interpretation; \\ $\mathrm{D}$ - writing the article; $\mathrm{E}$ - critical revision of the article; $\mathrm{F}$ - final approval of the article
}

Address for correspondence

Katarzyna Skośkiewicz-Malinowska

E-mail: kskoskiewicz@post.pl

Funding sources

Municipal Office of Wroclaw

Conflict of interest

None declared

Received on 0ctober 25, 2018

Reviewed on November 27, 2017

Accepted on February 20, 2019

Published online on March 7, 2019

Cite as

Skośkiewicz-Malinowska K, Malicka B, Ziętek M,

Kaczmarek U. Does oral dryness influence quality of life?

Current perspectives in elderly dental care. Adv Clin Exp Med.

2019;28(9):1209-1216. doi:10.17219/acem/104601

DOI

10.17219/acem/104601

Copyright

Copyright by Author(s)

This is an article distributed under the terms of the

Creative Commons Attribution Non-Commercial License

(http://creativecommons.org/licenses/by-nc-nd/4.0/)

\section{Abstract}

Background. The oral condition can functionally, socially and psychologically influence the quality of life. Oral dryness often occurs in the elderly due to the presence of systemic diseases and medications, which favors the development of many lesions and complaints, including dental caries, candidiasis, retention of full removable denture, taste disturbance and it enforces a change in nutrition.

Objectives. The aim of this study was to assess the impact of oral dryness on oral health-related quality of life in older subjects.

Material and methods. Five hundred subjects of both genders, aged 65 and over (mean $74.4 \pm 7.4$ ) were involved in the study. Oral dryness was evaluated clinically with use of the Challacombe scale (CODS, Clinical Oral Dryness Score). The oral health-related quality of life was assessed by the Oral Health Impact Profile scale (OHIP-14).

Results. Oral dryness occurred in $32.8 \%$ of subjects, most often on a mild level (29.6\%). The average value of the 0 HIP-14 scale was $8.01 \pm 13.59$. The regression analysis demonstrated a significant association between oral dryness and two domains of the OHIP-14 scale, i.e. functional limitation $(p<0.01)$ and psychological disability $(p<0.05)$.

Conclusions. Oral dryness is substantially related to the oral health-related quality of life, which indicates the necessity of monitoring oral dryness as part of routine dental care.

Key words: oral dryness, Oral Health Impact Profile, elderly, OHIP-14 
Extended human lifespan resulting from civilizational development along with decreased birth rate leads to an increase in the percentage of the elderly in comparison to younger people. This is the reason why, in recent years, the number of ageing members of society has been increasing, especially in highly developed countries. ${ }^{1,2}$ The ageing process of the human body is an inevitable phenomenon and it concerns all the organs. Changes related to the ageing process occurring in the oral cavity involve teeth, the periodontium, oral mucosa, bones of the jaws, temporomandibular joints, and salivary secretion. In elderly people, reduced salivary secretion (hyposalivation) is frequently observed; this condition leads to oral dryness (xerostomia). It is estimated that $25-30 \%$ of people aged 65 and over suffer from this condition and experience its symptoms. ${ }^{3,4}$ Data regarding stimulated salivary secretion among healthy elderly people does not indicate a significant and age-dependent reduction in secretion, but only an insignificant reduction in the secretion of seromucous glands (but not the serous gland, i.e. the parotid gland) in the conditions of minimal or prolonged stimulation. It has been observed that as people get older, the number of acini decreases, and the adipose and fibrous tissue increase. Small salivary glands also undergo these changes. However, reduction in the acinar part of the glands resulting from the ageing process does not significantly reduce the secretory function of the salivary glands. Therefore, it is currently assumed that the production of saliva and its composition does not change with age in healthy people. However, the observed dysfunction of salivary glands is mainly caused by consequent systemic diseases, pharmacotherapy and radiotherapy of the head and neck area. ${ }^{3,5-7}$ Taking medications is considered to be the most common cause of oral dryness, as most elderly people take at least one medication which negatively impacts salivary secretion. ${ }^{8}$ Medications that cause xerostomia include, among others, antihypertensive, anticholinergic, anti-reflux and cytotoxic medications, as well as diuretics, antidepressants and beta blockers. ${ }^{4,6}$ Furthermore, some common diseases at an older age may lead to the hypofunction of salivary glands (e.g., diabetes type 2 , and rheumatoid arthritis). Other causes include radiotherapy in the form of external radiation applied as part of head and neck cancer treatment, which destroys the tissues of the salivary glands and leads to long-lasting xerostomia.,

Reduced salivary secretion implies numerous clinical consequences, such as increased susceptibility to caries and periodontal diseases, which may then result in tooth loss, reduced denture tolerance, increased risk of fungal infections and taste disorders. People suffering from oral dryness have problems with eating (especially dry food, such as crackers or biscuits), speaking, swallowing and wearing removable partial dentures (their retention, pain experienced when wearing the dentures), as well as with the tongue tending to stick against the palate. Patients often report halitosis, burning mouth syndrome and intolerance to spicy food, excessive mucus or food accumulation. ${ }^{8}$ Moreover, patients frequently complain about oral dryness experienced particularly at night, as this is the time of the lowest salivary secretion. Intensified difficulties in speaking and eating may deteriorate the quality of social interactions. ${ }^{9}$

Oral health considerably affects the overall quality of life. It leads to a reduction in everyday activity and to lack of physical and/or mental wellbeing. Therefore, the notion of Health-related Quality of Life - HRQoL has been introduced. It is based on the WHO (World Health Organization) definition of health defined as "a state of complete physical, mental, and social well-being and not merely the absence of disease or infirmity". ${ }^{10-13}$ The relation between oral health and the quality of life can be determined by assessing to what extent oral health influences the quality of life through performing functions, such as chewing, biting, swallowing, speaking, as well as through mental wellbeing (satisfaction with dental aesthetics, self-esteem), physical wellbeing (comfort while eating and lack of discomfort or pain), and social wellbeing (feeling comfortable while speaking to others). ${ }^{14}$ One of the most commonly used assessment tools is the Oral Health Impact Profile (OHIP) scale that consists of 49 questions, or its shortened version, which consists of 14 questions (OHIP-14). ${ }^{15,16}$

\section{Objectives}

The aim of the study was to determine the influence of oral dryness on the oral health-related quality of life among elderly people.

\section{Material and methods}

\section{Recruitment and study duration}

The study was conducted for 24 months (from January 2015 to December 2016) after obtaining consent of the Bioethics Committee of Wroclaw Medical University KB 420/2015.

The study involved 500 subjects of both genders (180 men and 320 women) at the age of $\geq 65$ (mean age $74.4 \pm 7.4$, age range 65-99) who were urban residents of Wrocław. Data on the total number of 65 and over subjects living in the city was derived from the Central Statistical Office (Demographic Yearbook of Poland 2015). A minimum sample size was calculated based on data concerning caries prevalence in this age group with the assumed significance level of $95 \%$ and with $\pm 5 \%$ error tolerance. It turned out to be 383 ; therefore, the number of the examined subjects exceeded this figure.

\section{Survey inclusion/exclusion criteria}

The inclusion criteria for the study were the following: age of 65 and over, place of residence (citizens of Wrocław), able to communicate and a written consent to participate in the survey. 
The exclusion criteria were lack of a written consent or mental disorders which would have made filling out the questionnaire impossible.

The participation in the survey was voluntary. The patients were enrolled based on information provided in press, on the radio and on the Internet, as well as in Senior Citizens Associations, at the University of the Third Age, church organizations, primary care outpatient clinics, pharmacies, and residential homes.

\section{Survey execution}

\section{Sociomedical examination}

The demographic and personal information, and medical history were obtained from the subjects. The data included the date of birth and gender, marital status, level of education, and amount of monthly income before the appointment; the patients were asked to provide written information about current and past diseases, as well as medications currently taken by them. Medical data comprised the type of past and present diseases and medicine taken.

\section{Clinical oral examinations}

Oral dryness was determined according to the Challacombe Scale which serves as the Clinical Oral Dryness Score - CODS. It includes 10 characteristics: 1) mirror sticks to oral mucosa; 2) mirror sticks to tongue; 3) saliva frothy; 4) no saliva pooling in floor of mouth; 5) tongue shows generalized shortened papillae (mild depapillation); 6) altered gingival architecture (i.e. smooth); 7) glassy appearance of oral mucosa, especially palate; 8 ) tongue lobulated/fissured; 9) cervical caries (more than two teeth); 10) debris on palate or sticking to teeth. One score is assigned to each sign. Scores 1-3 indicate a mild, 4-6 a moderate and 7-10 a severe oral dryness. ${ }^{17,18}$

\section{Psychometric examination}

Oral health-related quality of life was assessed with the use of the Oral Health Impact Profile-14 scale (OHIP-14). ${ }^{16,17}$ It consists of 14 questions related to problems which have occurred within the past month, and which are connected with teeth, oral cavity or wearing dentures. The problems include: 1 ) trouble with pronouncing words, 2) worsened taste, 3) pain, 4) discomfort while eating, 5) self-consciousness, 6) emotional tension, 7) unsatisfactory diet, 8) interrupted meals, 9) difficulty with relaxing, 10) embarrassments, 11) irritability, 12) inability to complete everyday tasks, 13) reduced satisfaction with life, (14) complete inability to function. The answers to the questions were categorized in accordance with the frequency of occurrence on a five-level scale ranging from never (score 0 ), hardly ever (score 1), occasionally (score 2), fairly often (score 3) to very often (score 4). Oral health-related quality of life is expressed as the sum of the score for the 14 questions (OHIP-14 sum, maximum 56 points). Furthermore, the 14 questions constitute 7 domains. The domains are related to functional limitations, pain (physical), psychological discomfort, physical disability, psychological disability, social disability and handicap (infirmity). The OHIP-14 scale has been validated for the Polish population. ${ }^{17}$

\section{Statistical analysis}

Continuous variables were presented as mean values with standard deviation or, if not normally distributed, as median and range, while categorical variables were reported as percentages and numbers. As the empirical distributions of quantitative variables differed significantly from the theoretical normal distribution (they were skewed), they were transformed using the Box-Cox technique. Continuous variables were compared by $t$-test, while categorical variables were compared by $X^{2}$ test or Fisher's exact test. An analysis of variance (ANOVA) was performed to compare the mean values of transformed value between the OHIP-14 domains. The significance of the relationship between the oral dryness and the predictors analyzed was verified using the Pearson chi-square test or the exact Fisher test. For each predictor, odds ratio adjusted by age and sex was calculated. Its significance was verified using the Mantel-Haenszel test. A two-tailed value of $\mathrm{p}<0.05$ was used to reject the null hypothesis. All statistical analyses were performed using STATISTICA v. 13 (StatSoft, Inc., Tulsa, USA).

\section{Results}

\section{Sociodemographic characteristics of the subjects}

Most of the subjects lived with a family member (62.0\%) and were independent (90.8\%). Secondary education was completed by $51.0 \%$ of the subjects, primary education by $16.2 \%$, and higher education by $32.8 \%$. High monthly income per person was declared by $27.2 \%$, medium income by $45.2 \%$, and low income by $25.6 \%$. The remaining $1.8 \%$ did not provide their answers.

\section{The subjects' medical history}

Only $14 \%$ of the subjects did not report the occurrence of a chronic systemic disease. Most often, there were two coexisting systemic disorders (27.0\%). Over $60 \%$ of the subjects reported hypertension, and over $20 \%$ diabetes (Table 1). 
Table 1. General information of the patients

\begin{tabular}{|c|c|c|}
\hline \multirow[t]{2}{*}{ Parameters } & Quality variables & $\begin{array}{c}\text { Quantitative } \\
\text { variables }\end{array}$ \\
\hline & $\%(n)$ & Me (min-max) \\
\hline Age [years] & & $73(65-99)$ \\
\hline Female & $64.0(320)$ & \\
\hline Oral dryness & $32.8(164)$ & \\
\hline OHIP-14 (total score) & & $1(0-56)$ \\
\hline D1 - functional limitation & & $0(0-8)$ \\
\hline D2 - pain & & $0(0-8)$ \\
\hline D3 - psychological discomfort & & $0(0-8)$ \\
\hline D4 - physical disability & & $0(0-8)$ \\
\hline D5 - psychological disability & & $0(0-8)$ \\
\hline D6 - social disability & & $0(0-8)$ \\
\hline D7 - handicap & & $0(0-8)$ \\
\hline Number of medications & & $2(0-6)$ \\
\hline Number of diseases & & $2(0-7)$ \\
\hline Hypertension & $62.4(312)$ & \\
\hline Diabetes & 21.8 (109) & \\
\hline Hypercholesterolemia & $18.4(92)$ & \\
\hline Rheumatoid arthritis & $14.6(73)$ & \\
\hline Hypothyroidism & $11.2(56)$ & \\
\hline Reflux & $9.8(49)$ & \\
\hline Heart failure & $7.4(37)$ & \\
\hline Kidney disease & $7.6(38)$ & \\
\hline Asthma & $6.6(33)$ & \\
\hline Infarction & $5.2(26)$ & \\
\hline Cancer & $5.8(29)$ & \\
\hline Hyperthyroidism & $4.4(22)$ & \\
\hline
\end{tabular}

\section{Oral dryness}

Oral dryness was found in $32.8 \%$ of the subjects of both genders (Table 1), including mild dryness in 29.6, moderate - in $3.0 \%$ and severe - in $0.2 \%$. Among women, the condition was significantly more common than among men $(36.9 \%$ vs $25.6 \%, \mathrm{p}=0.025)$. The most frequent symptoms included the mouth mirror tending to stick against buccal mucosa $-26.6 \%$ (more often among women than men $30.6 \%$ vs $18.3 \%, \mathrm{p}=0.000$ ) or against the tongue $-22.2 \%$ (slightly more often in women than in men $25.3 \%$ vs $17.8 \%, p=0.068$ ); the least common symptoms were cervical caries involving $>2$ teeth $-1.0 \%$ $(0.6 \%$ in men and $1.3 \%$ in women, $\mathrm{p}=0.779)$ and debris on palate or sticking to teeth $0.8 \%$ ( $1.1 \%$ in men, $0.6 \%$ in women, $\mathrm{p}=0.622$ ).

\section{OHIP-14 scale}

The total OHIP-14 score (sum) for all the subjects was $8.01 \pm 13.59$ and it did not reveal a gender-related difference $(7.20 \pm 12.90$ in men and $8.50 \pm 14.00$ in women, $\mathrm{p}=0.280$ ).

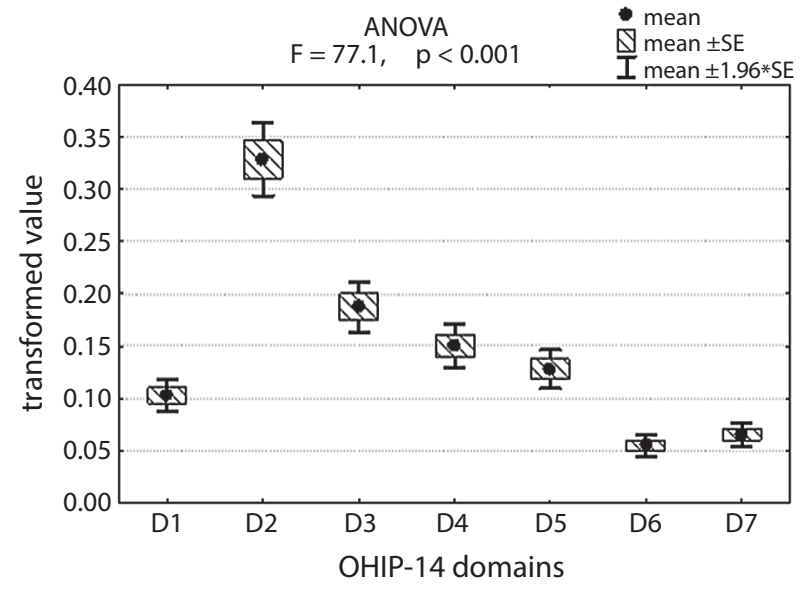

Fig. 1. Domains of OHIP-14

D1 - functional limitations; D2 - pain (physical); D3 - psychological discomfort; D4 - physical disability; D5 - psychological disability; D6 - social disability; D7 - handicap.

Regarding domains, it turned out that the subjects most frequently reported physical pain (D2) and physical discomfort (D3) (Fig. 1). Moreover, significant differences among all the domains were found, except for domains D6 and D7. When considering OHIP-14 scale transformed values adjusted by sex and age in groups that differed in oral dryness, we found higher mean total OHIP-14 score in a subgroup with oral dryness $(p=0.027)$. The subjects with oral dryness symptoms significantly more often reported trouble with pronouncing words $(0.054 \pm 0.088$ vs $0.029 \pm 0.071$, $\mathrm{p}=0.001)$, worsened taste $(0.073 \pm 0.115$ vs $0.045 \pm 0.098$, $\mathrm{p}=0.004)$, difficulty with relaxing $(0.061 \pm 0.105$ vs $0.039 \pm 0.089, \mathrm{p}=0.015)$, and complete inability to function $(0.036 \pm 0.076$ vs $0.021 \pm 0.061, \mathrm{p}=0.02)$ (Table 2$)$.

\section{Regression analysis}

Results of multiple regression between OHIP-14 domains (transformed) and the studied variables (Table 3) showed the correlation of domain 1 (functional limitation) and 5 (psychological disability) with oral dryness, domain 2 (pain) with number of medication, domain 3 (psychological discomfort) and 5 (psychological disability) and kidney diseases, and domain 4 (physical disability) with cardiac infarction (Table 3).

Gender, age over 70 years, the value of the OHIP-14 scale higher than 0 , as well as some coexisting systemic diseases, such as hypertension, cardiac infarction, kidney disease and hypothyroidism, were independent predictors of oral dryness. It was noticed that women had almost as twice as high probability to suffer from oral dryness than men $(\mathrm{OR}=1.70)$. A similar observation was made with regards to patients aged over 71 years who provided a positive answer to at least 1 question included in the OHIP-14 scale. Patients suffering from cardiac infarction were twice as prone to suffer from oral dryness as those who were not afflicted with the disease $(\mathrm{OR}=2.04)$. Patients 
Table 2. Mean transformed values of OHIP-14 scale adjusted by sex and age in relation to oral dryness

\begin{tabular}{|c|c|c|c|c|}
\hline \multirow{2}{*}{ No } & \multirow{2}{*}{ Items } & No oral dryness & Oral dryness & \multirow{2}{*}{$p$-value* } \\
\hline & & $\mathrm{M}^{\top} \pm \mathrm{SD}$ & $\mathrm{M}^{\top} \pm \mathrm{SD}$ & \\
\hline 1 & Trouble with pronouncing words & $0.029 \pm 0.071$ & $0.054 \pm 0.088$ & 0.001 \\
\hline 2 & Worsened taste & $0.045 \pm 0.098$ & $0.073 \pm 0.115$ & 0.004 \\
\hline 3 & Pain & $0.131 \pm 0.203$ & $0.150 \pm 0.208$ & 0.321 \\
\hline 4 & Discomfort while eating & $0.157 \pm 0.232$ & $0.173 \pm 0.234$ & 0.480 \\
\hline 5 & Self-consciousness & $0.119 \pm 0.190$ & $0.135 \pm 0.196$ & 0.401 \\
\hline 6 & Emotional tension & $0.089 \pm 0.153$ & $0.098 \pm 0.157$ & 0.542 \\
\hline 7 & Unsatisfactory diet & $0.088 \pm 0.153$ & $0.097 \pm 0.159$ & 0.532 \\
\hline 8 & Interrupted meals & $0.058 \pm 0.114$ & $0.072 \pm 0.123$ & 0.203 \\
\hline 9 & Difficulty with relaxing & $0.039 \pm 0.089$ & $0.061 \pm 0.105$ & 0.015 \\
\hline 10 & Embarrassment & $0.071 \pm 0.134$ & $0.092 \pm 0.146$ & 0.113 \\
\hline 11 & Irritability & $0.041 \pm 0.105$ & $0.047 \pm 0.106$ & 0.437 \\
\hline 12 & Inability to complete everyday tasks & $0.024 \pm 0.064$ & $0.030 \pm 0.071$ & 0.305 \\
\hline 13 & Reduced satisfaction with life & $0.045 \pm 0.095$ & $0.048 \pm 0.097$ & 0.733 \\
\hline 14 & Complete inability to function & $0.021 \pm 0.061$ & $0.036 \pm 0.076$ & 0.020 \\
\hline \multicolumn{2}{|c|}{ Total OHIP-14 (sum) } & $0.717 \pm 0.821$ & $0.891 \pm 0.812$ & 0.027 \\
\hline
\end{tabular}

* t-test values.

Table 3. Results of multiple regression - standardized coefficient regression values (Beta) between OHIP-14 domains (transformed) and the studied variables

\begin{tabular}{|l|c|c|c|c|c|c|}
\hline \multicolumn{1}{|c|}{ Variables } & $\begin{array}{c}\text { Functional } \\
\text { limitation (D1) }\end{array}$ & $\begin{array}{c}\text { Pain } \\
\text { (D2) }\end{array}$ & $\begin{array}{c}\text { Psychological } \\
\text { discomfort (D3) }\end{array}$ & $\begin{array}{c}\text { Physical } \\
\text { disability } \\
\text { (D4) }\end{array}$ & $\begin{array}{c}\text { Psychological } \\
\text { disability } \\
\text { (D5) }\end{array}$ & $\begin{array}{c}\text { Social } \\
\text { disability } \\
\text { (D6) }\end{array}$ \\
\hline Age $^{\top}$ & -0.022 & 0.028 & -0.019 & -0.013 & -0.002 \\
Hemalicap \\
(D7)
\end{tabular}

$\mathrm{Age}^{\top}$ - transformed age of patients; NoM ${ }^{\top}$ - transformed number of medication; significance level: ${ }^{*} p<0.05,{ }^{* *} p<0.01,{ }^{* *} p<0.001$.

suffering from kidney disease were 3 times more likely to develop oral dryness than patients who did not have the disease $(\mathrm{OR}=2.75)$. In subjects with hypothyroidism, oral dryness was over 2 times more likely to occur than in patients who did not suffer from the disease $(\mathrm{OR}=2.17)$ (Table 4).

\section{Discussion}

Oral dryness resulting from reduced salivary secretion can be detected with the use of various methods: by asking about symptoms (e.g., the Fox's test), asking about some systemic diseases and medications taken, measuring the stimulated and unstimulated salivary flow (sialometry), physical examination, salivary glands imaging and biopsy, and analyzing biochemical components of the saliva and serum. ${ }^{6,8}$ During the clinical examination, there is an attempt to identify symptoms of oral dryness, including glassy appearance of oral mucosa, mirror sticking to buccal mucosa, dry, painful and lobulated tongue, sticky and frothy saliva, no saliva pooling in mouth floor, turbid saliva flowing out of the salivary duct, as well as enlarged and painful salivary glands. Reduced salivary secretion results in cervical caries, accumulation of food particles due to oral clearance reduction, candidiasis, and angular cheilitis. Among subjects wearing removable dentures, reduced retention or denture intolerance resulting from lower lubrication of the tissue base and the denture plate are observed. This leads to reduced adhesion and disturbance in the distribution of occlusal forces. ${ }^{19-23}$

In our study, oral dryness was clinically assessed with the use of the Challacombe Scale that includes 10 characteristic symptoms related to saliva shortage in the oral 
Table 4. Results of chi-square test

\begin{tabular}{|c|c|c|c|c|c|c|}
\hline \multirow[b]{2}{*}{ Oral dryness predictors } & \multicolumn{2}{|c|}{ Oral dryness } & \multicolumn{2}{|c|}{ Chi-square test } & \multirow[b]{2}{*}{$\mathrm{OR}$} & \multirow[b]{2}{*}{$95 \% \mathrm{Cl}$} \\
\hline & $\begin{array}{c}\text { Yes } \\
\mathrm{n}=164\end{array}$ & $\begin{array}{c}\text { No } \\
n=336\end{array}$ & $x^{2}$ & $p$-value & & \\
\hline Female & $72.0(118)$ & $60.1(202)$ & 6.70 & 0.010 & 1.70 & $1.14-2.55$ \\
\hline Age $>71$ years & $64.6(106)$ & $51.8(174)$ & 7.38 & 0.007 & 1.70 & $1.16-2.50$ \\
\hline OHIP-14 $>0$ & $46.1(155)$ & $59.2(97)$ & 4.34 & 0.037 & $1.62^{\mathrm{a}}$ & $1.10-2.40$ \\
\hline Hypertension & $71.3(117)$ & $58.0(195)$ & 4.23 & 0.040 & $1.67^{\mathrm{a}}$ & $1.11-2.52$ \\
\hline Hypercholesterolemia & $19.5(32)$ & $17.9(60)$ & 0.06 & 0.608 & $1.00^{\mathrm{a}}$ & $0.60-1.68$ \\
\hline Diabetes & $26.8(44)$ & $19.4(65)$ & 1.34 & 0.248 & $1.46^{\mathrm{a}}$ & $0.91-2.32$ \\
\hline Infarction & $8.5(14)$ & $3.6(12)$ & 4.55 & 0.033 & $2.04^{a}$ & $1.04-4.28$ \\
\hline Heart failure & $6.1(10)$ & $8.0(27)$ & 0.35 & 0.552 & $0.74^{\mathrm{a}}$ & $0.35-1.57$ \\
\hline Asthma & $7.3(12)$ & $6.2(21)$ & 0.07 & 0.795 & $1.18^{\mathrm{a}}$ & $0.57-2.47$ \\
\hline Reflux & $8.5(14)$ & $10.4(35)$ & 0.44 & 0.507 & $0.80^{\mathrm{a}}$ & $0.42-1.54$ \\
\hline Kidney disease & $12.8(21)$ & $5.1(17)$ & 5.14 & 0.023 & $2.75^{\mathrm{a}}$ & $1.19-6.36$ \\
\hline Hyperthyroidism & $6.7(11)$ & $3.3(11)$ & 2.33 & 0.127 & $2.12^{\mathrm{a}}$ & $0.90-5.01$ \\
\hline Hypothyroidism & $17.1(28)$ & $8.3(28)$ & 7.61 & 0.006 & $2.17^{\mathrm{a}}$ & $1.14-4.16$ \\
\hline Cancer & $3.7(6)$ & $6.8(23)$ & 1.51 & 0.220 & $0.52^{\mathrm{a}}$ & $0.21-1.30$ \\
\hline Rheumatoid arthritis & $19.5(32)$ & $12.2(41)$ & 1.38 & $0.241^{\mathrm{a}}$ & $1.57^{\mathrm{a}}$ & $0.93-2.64$ \\
\hline
\end{tabular}

${ }^{a}$ - adjusted by gender and age; ${ }^{b}-$ Fisher's exact test; ${ }^{c}-$ adjusted by age.

cavity. ${ }^{17}$ The Clinical Oral Dryness Score (CODS), which consists of a 10-point scale with each point representing a feature of dryness in the mouth, may, in accordance with the current state of knowledge, be used individually during routine clinical assessment to detect hyposalivation. ${ }^{18}$

Overall, oral dryness was determined in $32.8 \%$ of the subjects and that included $29.6 \%$ of mild dryness, $3.0 \%$ of moderate dryness and $0.2 \%$ of severe dryness. Among women, dry mouth occurred significantly more frequently than in men $(36.9 \%$ vs $25.6 \%, p=0.025)$, which was consistent with the results of other studies. ${ }^{24-28}$ Niklander et al. found the occurrence of xerostomia in among 13\% of women and half that many in men $(6.1 \%)$ at the age of $18-83$ years with a mean age of 46 years. ${ }^{29}$ They observed the highest prevalence in subjects aged $68-77$ years (33.3\%), followed by patients aged $78-83$ years (22.27\%).

A study conducted in India revealed that $58.6 \%$ of the 55-75-year-old and older subjects perceived dryness of mouth. ${ }^{30}$ Among Korean subjects aged 55 years and over, the occurrence of at least 1 symptom of xerostomia was observed in $70.1 \%$ of the subjects, and in $25.8 \%$, the observed symptoms were severe. ${ }^{31}$ At the age of 60 and over (average age of 67.5 years), reduced secretion of stimulated saliva was observed in 64\% subjects from Saudi Arabia. ${ }^{32}$ Age-dependent occurrence of xerostomia was identified and it ranged from $5 \%$ in the group aged $18-25$ years to $16 \%$ in the group aged 65-67 years, and to as much as $26 \%$ in the group aged 75 and over. ${ }^{28}$

Salivary glands function can be injured by many systemic diseases based on different mechanisms with the resulting complication of oral dryness. ${ }^{33}$ Our data showed a significantly higher number of co-morbid diseases in the subjects with clinical symptoms of dry mouth. Elderly people suffering from chronic diseases are on longterm therapy using polypharmacy. Hundreds of medicines induce oral dryness; some of them can exert a synergistic effect on the salivary secretion. Hence, drug-induced dry mouth is one of the most common oral problems in elderly individuals. ${ }^{34}$ Our data showed a significantly higher mean number of administered medicines among the subjects presenting oral dryness symptoms compared to these with no symptoms. Similar observations were made by Bogucki et al., who identified a correlation between xerostomia, medication taken by patients, age, gender and past diseases. $^{35}$

The total OHIP-14 score in the examined subjects aged 65 and over was $8.01 \pm 13.59$ and it did reveal a significant difference related to the gender. Comparing the figure in the same age group of different populations, we noticed a slightly higher value (8.88) in Spain ${ }^{36}, 2.8$-fold higher (22.4) in Iran ${ }^{37}$ and 2.7-fold lower (2.9) in the United Kingdom. ${ }^{38}$ In our study, a significantly higher total OHIP-14 score was found in the subjects with clinical symptoms of oral dryness, indicating a poorer quality of life related to oral health (OHRQoL). Similar conclusions were made by Locker, who conducted research among a group of 225 subjects in a long-term care setting (average age: 83 years) and who observed a major influence of xerostomia on the well-being and quality of life of the population. ${ }^{39}$

The finding was consistent with the study performed in subjects aged $18-75$ years and over in whom the total OHIP-14 score was ca. $50 \%$ higher (6.3 vs 3.5 ) in the patients with xerostomia determined by a response to one 
item: "How often does your mouth feel dry?"28 Another study involving subjects aged 18-87 years also presented a significantly higher total OHIP-14 score in patients with xerostomia than in patients without xerostomia (20.1 vs 12.7). ${ }^{29}$ A Japanese study performed on the elderly (mean age 66.1) showed that higher values of the OHIP-14 score were related to the perception of dry mouth on eating and hyposalivation. ${ }^{40}$ Our results indicated a relationship between oral dryness and 2 OHIP-14 domains: functional limitation and psychological disability. The Chilean study, which revealed more reduced OHRQoL in a group of patients with xerostomia, concluded that the highest impact was detected for the domains of psychological discomfort, psychological incapacity and physical pain. ${ }^{29}$

Own data indicated that gender, age over 70 years, the value of the OHIP-14 scale higher than 0 , as well as some coexisting systemic diseases were independent predictors of oral dryness.

Several limitations have to be considered in a discussion about the results of this study. Firstly, this study was conducted using a self-reported questionnaire to report data such as OHIP-14, which could lead to identification bias. However, some studies showed the use of this scale to be a valid and reliable method of screening for oral healthrelated quality of life.

Secondly, the use of survey data did not allow us to explain temporal relationships or to show inferences on causality. Thirdly, while analyzing the obtained results, it is essential to bear in mind a possible self-selection error of the study participants, i.e., the participants who joined the study were worried that they were having dental problems, or they were aware of their dental problems and were looking for help; also, there may have been those who refused to participate in the study due to dental fear. Moreover, another interfering factor resulted from the application of the exclusion criteria. Finally, excluding patients with a mental disorder might have constituted another interfering factor.

\section{Conclusions}

Individuals with oral dryness symptoms had poorer oral health-related quality of life having a higher mean of the total OHIP-14 score than their counterparts without any symptoms. The findings support the view that oral dryness negatively affects everyday life; therefore, there is a necessity to monitor oral dryness during the routine dental care as well as to ensure the cooperation of the dentist with general practitioner to diminish oral dryness severity caused by medication.

\section{References}

1. World Report on Ageing and Health. WHO, 2015. http://apps.who. int/iris/bitstream/10665/186463/1/9789240694811_eng.pdf?ua=1 Accessed on June 23, 2018.
2. Ferrucci L, Guralnik JM, Studenski S, Fried LP, Cutler GB Jr, Walston JD. Designing randomized, controlled trials aimed at preventing or delaying functional decline and disability in frail, older persons: a consensus report. J Am Geriatr Soc. 2004 Apr;52(4):625-634.

3. Vissink A, Spijkervet FK, Van Nieuw Amerongen A. Aging and saliva: A review of the literature. Spec Care Dentist. 1996;16:95-103.

4. Gupta A, Epstein JB, Sroussi H. Hyposalivation in elderly patients. J Can Dent Assoc. 2006;72:841-846.

5. Razak PA, Richard KMJ, Thankachan RP, Hafiz KAA, Kunar KN, Sameer KM. Geriatric oral health: A review article. J Int Oral Health. 2014;6: 110-116.

6. Kaczmarek U. Xerostomia - aetiology, prevalence and diagnosis - on the basis of literature [in Polish]. Czas Stomat. 2007;60(1):20-31.

7. Malicka B, Kaczmarek U, Skośkiewicz-Malinowska K. Prevalence of xerostomia and the salivary flow rate in diabetic patients. Adv Clin Exp Med. 2014;23(2):225-233.

8. Henson BS, Inglehart MR, Eisbruch A, Ship JA. Preserved salivary output and xerostomia-related quality of life in head and neck cancer patients receiving parotid-sparing radiotherapy. Oral Oncol. 2001;37: 84-93.

9. Ship JA, Pillemer SR, Baum BJ. Xerostomia and the geriatric patient. J Am Geriatr Soc. 2002;50:535-543.

10. Wagner M, Rietz C, Kaspar R, et al. Quality of life of the very old: Survey on quality of life and subjective well-being of the very old in North Rhine-Westphalia (NRW80+). Z Gerontol Geriatr. 2018;51(2): 193-199.

11. Lima MG, Barros MB, César CL, Goldbaum M, Carandina L, Ciconelli RM Health related quality of life among the elderly: A population-based study using SF-36 survey. Cad Saude Publica. 2009;25(10):2159-2167.

12. Conrad I, Matschinger H, Riedel-Heller S, von Gottberg C, Kilian R. The psychometric properties of the German version of the WHOQOL-OLD in the German population aged 60 and older. Health Qual Life Outcomes. 2014;5(12):105-108.

13. Locker D. Concepts of oral health, disease and the quality of life. In: Measuring oral health and quality of life. GD Slade. Chapell Hill eds., University of North Carolina. Dental Ecolog. 1997;11-24.

14. Inglehart MR. Oral health and quality of life. Pocket dentistry. https:// pocketdentistry.com/2-oral-health-and-quality-of-life/Dostęp: 15.12. 2017

15. Slade GD, Spencer AJ. Development and evaluation of the oral health impact profile. Community Dent Health. 1994;11:3-11.

16. Skośkiewicz-Malinowska K, Kaczmarek U, Ziętek M, Malicka B. Validation of the Polish version of the oral health impact profile-14. Adv Clin Exp Med. 2015;24:129-137.

17. The Challacombe scale of clinical oral dryness https://www.dentalhealth.org. 15.12.2017.

18. Jager DHJ, Bots CP, Forouzanfar T, Brand HS. Clinical oral dryness score: Evaluation of a new screening method for oral dryness. Odontology. 2018;22. doi:10.1007/s10266-018-0339-4

19. Fox PC, van der Ven F, Sonie BC, Weiffenbach JM, Baum BJ. Xerostomia: evaluation of symptoms with increasing significance. Jam Dent Assoc. 1985;110:519-525.

20. Guggenheimer J, Moore PA. Xerostomia: etiology, recognition and treatment. J Am Dent Assoc. 2003;134:61-69.

21. Navazesh M. How can oral health care providers determine if patients have dry mouth? J Am Dent Assoc. 2003;134:613-618.

22. Millsop JW, Wang EA, Fazel N. Etiology, evaluation, and management of xerostomia. Clin Dermatol. 2017;35:468-476.

23. Rayman S, Dincer E, Almas K. Xerostomia. Diagnosis and management in dental practice. N Y State Dent J. 2010;76:24-27.

24. National Institute of Dental and Crianiofacial Research. Tooth Loss in Seniors (Age 65 and Over) https://www.nidcr.nih.gov/DataStatistics/FindDataByTopic/ToothLoss/ToothLossSeniors65andOlder.htm

25. Tyrovolas S, Koyanagi A, Panagiotakos DB, Haro JM, Kassebaum NJ, Kotsakis GA. Population prevalence of edentulism and its association with depression and self-rated health. Sci Rep. 2016;6:37083.

26. Müller F, Shimazaki Y, Kahabuka F, Schimmel M. Oral health for an ageing population: The importance of a natural dentition in older adults. Int Dent J. 2017;67(Suppl 2):7-13.

27. Kamińska-Pikiewicz K, Bachanek T, Chałas R. The incidence of oral dryness in people over 65 years living in Lublin. Curr Issues Pharm Med Sci. 2015;28:250-253. 
28. Benn AM, Broadbent JM, Thomson WM. Occurrence and impact of xerostomia among dentate adult New Zealanders: findings from a national survey. Aust Dent J. 2015;60(3):362-367.

29. Niklander S, Veas L, Barrera C, Fuentes F, Chiappini G, Marshall M. Risk factors, hyposalivation and impact of xerostomia on oral healthrelated quality of life. Braz Oral Res. 2017;16(31):e14. doi:10.1590/18073107BOR-2017.vol31.0014

30. Bharateesh JV, Kokila G. Association of root caries with oral habits in older individuals attending a rural health centre of a dental hospital in India. J Clin Diagn Res. 2014;8(11):ZC80-ZC82.

31. So JS, Chung SC, Kho HS, Kim YK, Chung JW. Dry mouth among the elderly in Korea: a survey of prevalence, severity, and associated factors. Oral Surg Oral Med Oral Pathol Oral Radiol Endod. 2010;110:475-483.

32. Ahmad MS, Bhayat A, Zafar MS, Al-Samadani KH. The impact of hyposalivation on quality of life (QoL) and oral health in the aging population of Al Madinah Al Munawarrah. Int J Environ Res Public Health. 2017;14(4).pii: E445. doi: 10.3390/ijerph14040445.

33. Mortazavi H, Baharvand M, Movahhedian A, Mohammadi M, Khodadoustan A. Xerostomia due to systemic disease: A review of 20 conditions and mechanism. Ann Med Health Sci Res. 2014;4(4):503-510.

34. Tan ECK, Lexomboon D, Sandborgh-Englund G, Haasum Y, Johnell K. Medications that cause dry mouth as an adverse effect in older people: A systematic review and metaanalysis. J Am Geriatr Soc. 2018; 66(1):76-84.
35. Bogucki ZA, Napadłek P, Dąbrowa T. A clinical evaluation denture adhesives used by patients with xerostomia. Medicine (Baltimore). 2015;94(7):e545-546.

36. Sáez-Prado B1, Haya-Fernández MC, Sanz-García MT. Oral health and quality of life in the municipal senior citizen's social clubs for people over 65 of Valencia, Spain. Med Oral Patol Oral Cir Bucal. 2016;21(6): e672-678.

37. Motallebnejad M, Mehdizadeh S, Najafi N, Sayyadi F. The evaluation of oral health-related factors on the quality of life of the elderly in Babol. Contemp Clin Dent. 2015;6(3):313-317.

38. Masood M, Newton T, Bakri NN, Khalid T, Masood Y. The relationship between oral health and oral health related quality of life among elderly people in United Kingdom. J Dent. 2017;56:78-83.

39. Locker D. Dental status, xerostomia and the oral health-related quality of life of an elderly institutionalized population. Spec Care Dentist. 2003;23(3):86-93.

40. Ikebe K, Matsuda K, Morii K, et al. Impact of dry mouth and hyposalivation on oral health-related quality of life of elderly Japanese. Oral Surg Oral Med Oral Pathol Oral Radiol Endod. 2007;103(2):216-222. 